\title{
Blended, Distance, Electronic and Virtual-Learning for the New Normal of Mathematics Education: A Senior High School Student's Perception
}

\author{
Carlo Patilan Cortez ${ }^{1 *}$ (iD
}

${ }^{1}$ STI College - Global City, Taguig City, PHILIPPINES

*Corresponding Author: carlo222009@yahoo.com

Citation: Cortez, C. P. (2020). Blended, Distance, Electronic and Virtual-Learning for the New Normal of Mathematics Education: A Senior High School Student's Perception. European Journal of Interactive Multimedia and Education, 1(1), e02001. https://doi.org/10.30935/ejimed/8276

\begin{abstract}
This study examines the perception of the senior high school students on blended, distance, electronic and virtual learning as a new way of delivering lessons for the following school year due to the existing threat of CoViD-19. A random sample of 342 senior high school students of different strands from STI College Global City served as the sample of this study. Data were collected through a self-administered survey questionnaire sent through a google form to comply with the existing lockdown policies of the government. The result indicates that the subjects' perception on the effectivity of online learning and their capability to attend the e-learning sessions is independent of their life style and available e-learning tools despite the result analysis of variance showing that their perceived mathematical capability are significantly different.
\end{abstract}

Keywords: blended learning, e-learning, e-learning tools, distance learning, perception, virtual learning

Received: 1 April $2020 \bullet$ Revised: 10 May $2020 \bullet$ Accepted: 13 May 2020

\section{INTRODUCTION}

Amidst the current situation of the society due to the existence of the pandemic CoViD-19 that affects not only the Philippines but all the countries over the world, learning delivery system is an issue that should be addressed as we move towards fighting the pandemic. Though e-Learning has been slowly being a part of the medium of instruction in the Philippine education, challenges have been evident on the use of it especially in Mathematics courses. Emerging question is that, is changing the new Norm of teaching Mathematics will be embraced by the current SHS students? There are 5 things to consider when shifting from Classroom training to e-Learning: Virtual Location and Access, Replicating Classroom Training, Assessment and Feedback, Cost Savings, and Jumping the Gun (Harris, 2017). Blended learning combined with synchronous and asynchronous types of teaching were suggested to be beneficial. The synchronous teaching proceeds in a real time, in which all participants accept the presented experience simultaneously and they can react mutually and asynchronous teaching is usually applied in different times to different students in which they can choose the pace and the way of accepting experience (Hubackova, 2015).

As part of the problem to be solved, question like "Is Internet connectivity will affect the perception of the students for distance learning?" comes out where internet connectivity should also be considered in the implementation of these types of teaching method. This is brought as a usual partner of a third world country such as the Philippines. Internet accessibility was described to be the "backbone" of online learning (Chantel 2002; LeLoup \& Ponterio, 2000). Without stable and efficient connection, students will only face a lot of frustrations instead of developing and enhancing literacy based on the new technology. It is the aspiration of educators to motivate distance learners, promote learning, and improve learners' engagement, thus maximized learners' learning outcomes in terms of good grades. But on a note, having a better technology to develop learning materials for the students will not ensure the effectivity of the materials itself. Educators need to educate themselves to be a good designer, content expert and competent to use technologies in terms of hardware and software to produce effective e-learning materials (Hasmawati et al., 2012). With the expected shift of educational delivery, a lot of adjustment must be done by the teachers not only on their preparation of teaching materials but likewise with the effectvity of their delivery having a different platform. But, with the convergence of technology comes the pedagogical challenges associated with elearning implementation, participation and acceptance rate from the learners should be less of a worry than how the school will cope with the development of an environment to ensure better learning of the students (Garcia, 2017).

Student's perception on this form of teaching, on the other hand, is relevant on which how will they receive a sudden shift of teaching styles offered by schools and to seek whether watching video tutorials and $\mathrm{e}$ 
Table 1. Economic status vs. Ability/Capability to attend virtual lectures

\begin{tabular}{|c|c|c|c|c|c|}
\hline \multirow[t]{2}{*}{ Economic Status } & \multicolumn{5}{|c|}{$\begin{array}{l}\text { Ability/capability to attend virtual lectures, watch videos of tutorials and comply with the requirements } \\
\text { if ever this will be the pattern of our classes next school year }\end{array}$} \\
\hline & Agree & Disagree & Strongly Agree & Strongly Disagree & Grand Total \\
\hline 0-9999 & 28 & 11 & 4 & 2 & 45 \\
\hline 10000-19999 & 55 & 21 & 5 & 8 & 89 \\
\hline 20000-29999 & 59 & 11 & 4 & 5 & 79 \\
\hline 30000-39999 & 27 & 7 & 1 & 4 & 39 \\
\hline 40000-49999 & 19 & 7 & 3 & 2 & 31 \\
\hline 50000 above & 41 & 13 & 2 & 3 & 59 \\
\hline Grand Total & 229 & 70 & 19 & 24 & 342 \\
\hline
\end{tabular}

learning decreases the need of students for validation. On a note, students' motivation on doing and accomplishing online learning materials must be considered as part of the factors (Zarlina Mohd Zamari et al., 2012).

As the current educational situation of the Philippines, it is somehow dictated by the existing Pandemic crisis that there will be a New Normal for the classroom teaching delivery with the virus threatening the health of the citizen of the country. With the existing practice of blended learning where classroom lecture prevails, it is now a question for the schools on how the classes will be addressed for the upcoming school year. Is the Willingness of the students to learn Mathematics using Electronic materials dependent to their economic status? Outcome -Based Education is currently applied as part of the curriculum where most of the activities and assessments are done in the four corners of the classroom. It is important to know, as part of the objective of this research, if the current status of the Senior High School students in STI College Global City will embrace this manner of shifting and is there a capacity for these Filipino students to maintain this kind of learning set-up.

\section{METHOD}

The research starts with the hypothesis that the students will be ready and embrace the BDEV or the Blended, Distance, Electronic and Virtual learning set up for the new normal of the senior high school students in learning mathematics. The research involved 342 students (205 males and 137 females) coming from different strands and chosen randomly and purposively from STI College Global City. The findings herein may not be generalizable among senior high school students in the national level scale. During the research, self administered survey questionnaires were distributed through bitly link and answered through google form. This is in compliance with enhanced Community Quarantine being followed in the Luzon. Answers were drawn and electronically summarized to show a simplified set of data. Quantitative research was being used in this paper with a mixed statistical method being applied.

The students of STI College Global City have been applying blended learning with the use eLMS or e-Learning Management System in the past 4 years with the aim of promoting blended learning and education through emerging technology. Students use and download materials through the platform and submit requirements and quizzes online. These students are the respondents for this research aiming to acquire knowledge regarding the strength of their internet connectivity, their available electronic gadgets at home, their source of internet connection, their perception with the effectiveness of a virtual classroom when they study mathematics considering that these students already managed to experience blended learning with the help of Learning Management System, their perception of electronic learning materials such as handouts, videos, PowerPoint and Learning Management System itself, motivation in doing elearning activities in eLMS, their perceived mathematical ability and the number of hours they spent browsing the internet per day. The research instrument contained Likert-scale to gauge the degree of agreeability of the respondent in each statement. It is then expected that the students will have a diverse responses for they have economical differences.

The data acquired from the responses of the students were sorted and presented in a descriptive manner. Numerical values were assigned to the ordinal data and were represented by a descriptive statistical tool. Relationship of the responses of the students with nominal data was compared using chi square. Contingency tables were presented to show relationship between two sets of data from the response of the students. Comparison in their perceived mathematical ability was done using the analysis of variance. The quantitative data gathered were encoded and treated with the help of Microsoft Excel program.

\section{RESULT}

In the survey conducted to 342 students (205 males, 137 females), whose ages are ranging from $16-22$ years old with majority of it is 16 (46\%) and 17 (36\%), the following were observed.

\section{Socio Economic Status vs. Capability to Attend Distance Learning}

Cross tabulating the students' economic status and their perceived capability of attending online classes, watch video of lessons and compliance with the school requirements, chi square test of independence was done. With the $\mathrm{X}^{2}=9.02, \mathrm{DF}=15, \mathrm{CV}=25$, it is found out that the economic status of the students is independent of their perception on their capability of performing e-Learning. It also showed that majority of the students (73\%) are capable of attending virtual lectures, watch videos of tutorials and comply with the requirements if ever this will be the pattern of their classes next school year (Table 1).

\section{Source of Internet Connection vs. Perception of Virtual Setting}

In the contingency table (Table 2) showing the source of internet connection of students and cross tabulated with their perception of Virtual Classes being as good as Classroom set up, $X^{2}=19.38, D F=15$, $\mathrm{CV}=25$, and it shows that the students' perception of a virtual classroom is independent of the kind of internet source they have at home. This shows that $63 \%$ of the students believes that virtual lectures are as good as the classroom lectures and $27 \%$ says that they only rely on prepaid mobile data. 
Table 2. Source of internet connection vs. Perception of Virtual Setting

\begin{tabular}{|c|c|c|c|c|c|}
\hline \multicolumn{6}{|c|}{ Perception of Virtual Setting is as good as Classroom Set up } \\
\hline Count of Source of internet connection & Agree & Disagree & Strongly Agree & Strongly Disagree & Grand Total \\
\hline 2 sources & 30 & 18 & 2 & 10 & 60 \\
\hline Cellphone prepaid Data & 55 & 23 & 6 & 8 & 92 \\
\hline more than 2 sources & 10 & 5 & 0 & 1 & 16 \\
\hline PostpaidWiFi & 21 & 6 & 5 & 3 & 35 \\
\hline Prepaid WiFi & 38 & 9 & 3 & 4 & 54 \\
\hline Router-Internet Service Provider & 42 & 28 & 3 & 12 & 85 \\
\hline Grand Total & 196 & 89 & 19 & 38 & 342 \\
\hline
\end{tabular}

Table 3. Gadgets the students owned vs. capability of attending online classes

\begin{tabular}{|c|c|c|c|c|c|}
\hline \multirow[t]{2}{*}{ Gadgets you own } & \multicolumn{5}{|c|}{$\begin{array}{c}\text { Capability of attending online classes, watch video of lessons and compliance with the school } \\
\text { requiremen ts }\end{array}$} \\
\hline & Agree & Disagree & Strongly Agree & Strongly Disagree & Grand Total \\
\hline Cellphone & 114 & 31 & 8 & 12 & 165 \\
\hline I own more than 2 gadgets & 37 & 8 & 3 & 2 & 50 \\
\hline Laptop Computer & 4 & 0 & 1 & 0 & 5 \\
\hline Notebook Computer & 0 & 1 & 0 & 0 & 1 \\
\hline Tablet & 1 & 0 & 0 & 0 & 1 \\
\hline Grand Total & 229 & 70 & 19 & 24 & 342 \\
\hline
\end{tabular}

Table 4. Quality of Internet Connection vs. Perception on Virtual Classroom

\begin{tabular}{|c|c|c|c|c|c|}
\hline \multirow{2}{*}{$\begin{array}{l}\text { Count of How is the Internet } \\
\text { Connectivity in your area }\end{array}$} & \multicolumn{5}{|c|}{$\begin{array}{c}\text { Virtual classrooms with the use of zoom or other video conference application will be as good as usual } \\
\text { classroom setting? }\end{array}$} \\
\hline & Agree & Disagree & Strongly Agree & Strongly Disagree & Grand Total \\
\hline Fair & 91 & 44 & 7 & 24 & 166 \\
\hline Poor & 30 & 23 & 4 & 8 & 65 \\
\hline Strong & 68 & 18 & 7 & 4 & 97 \\
\hline Very strong & 7 & 4 & 1 & 2 & 14 \\
\hline Grand Total & 196 & 89 & 19 & 38 & 342 \\
\hline
\end{tabular}

\section{Gadgets the Students Own vs. Capability of Attending Online} Classes

In the cross tabulation showing the relationship of the students Owned electronic gadgets and their perceived capability of attending online classes, watch video of lessons and compliance with the school requirements. With the $\mathrm{X}^{2=} 11.98, \mathrm{DF}=15, \mathrm{CV}=25$, it is found out that the electronic gadgets owned by the students has nothing to do with their perception on their capability of performing eLearning. This also shows that $48 \%$ of the students have their mobile phone alone as their electronic gadget at home and $73 \%$ believes that they are capable of attending the online classes (Table 3).

Quality of Internet Connection vs. Perception on Virtual Classroom

The cross tabulation between the quality of internet connection and their perception to virtual/online class was shown in Table 4. With the $X^{2}=16.1, D F=9, C V=16.92$, the quality of the internet connection of the students does not affect their perception on the effectivity of an online/virtual class.

Number of Hours Studen ts Spend in the Internet vs. Their Perception of the eLMS

Another cross tabulation showing the number of hours per day the students use in browsing the internet and their perception on how helpful the eLMS in studying Mathematics. With the $\mathrm{X}^{2}=51.3, \mathrm{DF}=36$, $\mathrm{CV}=49.8$, it is found that the perception of usefulness and helpfulness of the eLMS depends on the number of hours the students spend in browsing the internet (Table 5).

\section{Mean Response of the Students}

As shown in Table 6, the respondents agreed in all the situations as their responses have the mean between 2.51 to 3.25 . They agreed that video tutorials, PowerPoint, studying at home, validation of the teachers, to combine virtual and actual lectures, can all be beneficial. They also agreed also that they are capable to attend online and virtual classes and they believed in the capability of the school in managing this kind of situation. Their capability of understanding the handouts without any lectures has a mean response of 2.1 which shows that the students disagreed with the situation.

\section{SHS Strand and Their Perceived Mathematical Capability}

Table 7 summarizes the Perceived Mathematical ability of the sample students per strand while Table 8 shows the summary for the comparison of their mathematical abilities through analysis of variance. As the F-test is telling us that the differences among the perceived mathematical ability of the students are significant given that they are sorted according to their strand. 
Table 5. Number of hours students spend in the internet vs. their perception of the eLMS

\begin{tabular}{|c|c|c|c|c|c|c|}
\hline $\begin{array}{l}\text { How helpful was the eLMS to you in keeping up with the lessons } \\
\text { in your Math subjects? } 1 \text { as the least and } 10 \text { as being very helpful. }\end{array}$ & 1-2 hours & 3-4 hours & 5-6 hours & 7-8 hours & $\begin{array}{c}9 \text { hours and } \\
\text { up }\end{array}$ & Grand Total \\
\hline 1 & 0 & 1 & 0 & 1 & 0 & 2 \\
\hline 2 & 4 & 0 & 6 & 0 & 2 & 12 \\
\hline 3 & 0 & 3 & 0 & 6 & 0 & 9 \\
\hline 4 & 12 & 16 & 12 & 4 & 4 & 48 \\
\hline 5 & 35 & 65 & 70 & 30 & 85 & 285 \\
\hline 6 & 54 & 42 & 60 & 18 & 48 & 222 \\
\hline 7 & 42 & 91 & 84 & 56 & 112 & 385 \\
\hline 8 & 88 & 200 & 120 & 48 & 144 & 600 \\
\hline 9 & 45 & 225 & 72 & 81 & 72 & 495 \\
\hline 10 & 60 & 80 & 140 & 10 & 110 & 400 \\
\hline Grand Total & 340 & 723 & 564 & 254 & 577 & 2458 \\
\hline
\end{tabular}

Table 6. Mean Response of the Respondent

\begin{tabular}{cccc}
\hline Questions & Mean & SD & Interpretation \\
\hline Video Tutorials are very helpful in understanding math lessons & 3.01754386 & 0.626620449 & Agree \\
\hline I am capable of understanding Mathematics handouts without traditional lectures & 2.143274854 & 0.738508309 & disagree \\
\hline Online PowerPoint Presentations are effective to understand Math subjects. & 2.850877193 & 0.657451618 & Agree \\
\hline When i study math, i have better focus at home studying alone & 2.593567251 & 0.739552548 & Agree \\
\hline When i study math, i have better focus inside the classroom & 2.979532164 & 0.633513512 & Agree \\
\hline When i study math, i learn more when i watch video tutorials. & 2.894736842 & 0.681146451 & Agree \\
\hline When i study math using video tutorials, I still need validation from my teacher & 3.17251462 & 0.638045121 & Agree \\
\hline $\begin{array}{c}\text { Combination of Classroom lectures and Virtual/e-learning is more effective to me when studying math } \\
\text { subject. }\end{array}$ & 3.131578947 & 0.619996565 & Agree \\
\hline $\begin{array}{c}\text { Virtual classrooms with the use of zoom or other video conference application will be as good as usual } \\
\text { classroom setting? }\end{array}$ & 2.573099415 & 0.761370339 & Agree \\
\hline $\begin{array}{c}\text { I will be able/capable to attend virtual lectures, watch videos of tutorials and comply with the } \\
\text { requirements if ever this will be the pattern of our classes next school year }\end{array}$ & 2.710526316 & 0.677112433 & Agree \\
\hline $\begin{array}{c}\text { I am confident that my school will be able consider the students and cope with the possible New Normal } \\
\text { in Classroom Settings }\end{array}$ & 2.979532164 & 0.580364748 & Agree \\
\hline
\end{tabular}

Table 7. Chi Square Summary

\begin{tabular}{cccccc}
\hline \multicolumn{7}{c}{ Test of Independence Summary } & & & \\
\hline Table & $\mathbf{1}$ & $\mathbf{2}$ & $\mathbf{3}$ & $\mathbf{4}$ & $\mathbf{5}$ \\
\hline Chi-Square & 19.38 & 9.02 & 11.98 & 51.3 & 16.1 \\
\hline DF & 15 & 15 & 15 & 36 & 9 \\
\hline CV & 25 & 25 & 25 & 49.8 & 16.92 \\
\hline Remarks & Ind & Ind & ind & Dep & Ind \\
\hline
\end{tabular}

Table 8. Strand vs. Perceived Mathematical Capability

\begin{tabular}{|c|c|c|c|c|c|c|c|c|c|c|}
\hline \multirow{2}{*}{ STRAND } & \multicolumn{10}{|c|}{ Perceived Mathematical Capability } \\
\hline & 2 & 3 & 4 & 5 & 6 & 7 & 8 & 9 & 10 & Grand Total \\
\hline $\mathrm{ABM}$ & 2 & 3 & 2 & 6 & 8 & 5 & 4 & 0 & 0 & 30 \\
\hline CCT & 0 & 0 & 3 & 9 & 7 & 7 & 2 & 1 & 0 & 29 \\
\hline Culinary Art & 0 & 0 & 4 & 10 & 7 & 6 & 6 & 0 & 1 & 34 \\
\hline MAWD & 0 & 2 & 11 & 29 & 13 & 21 & 15 & 5 & 1 & 97 \\
\hline $\mathrm{RBO}$ & 0 & 0 & 0 & 3 & 2 & 2 & 1 & 0 & 2 & 10 \\
\hline STEM & 1 & 1 & 9 & 25 & 22 & 31 & 30 & 3 & 2 & 124 \\
\hline TOP & 0 & 0 & 1 & 6 & 1 & 6 & 3 & 1 & 0 & 18 \\
\hline Grand Total & 3 & 6 & 30 & 88 & 60 & 78 & 61 & 10 & 6 & 342 \\
\hline
\end{tabular}

Table 9. Analysis of variance for the Students' Perceived Mathematical Ability per Strand

\begin{tabular}{ccccc}
\hline & & & & \\
\hline Sources of Variation & Sum of Squares & Degree of Freedom & Mean of Squares & F-value \\
\hline Within & 771.3 & $\mathrm{n}-\mathrm{k}=335$ & 2.30 & 2.2 \\
\hline Between & 29.8 & $\mathrm{k}-1=6$ & 4.97 & $\mathrm{CV}=2.1$ \\
\hline Total & 801.1 & $\mathrm{n}-1=341$ & & Reject \\
\hline Remarks & & & & \\
\hline
\end{tabular}




\section{DISCUSSION}

The data have given much ideas in order to understand the perception of the respondents regarding BDEV-learning. The discussion in this research will revolve around the relationships of the students' life style which includes their socio economic status and available e-learning tools to their perception of Blended, Distance, Electronic and Virtual learning.

Socio Economic Capability, Technology, and BDEV-Learning amidst CoViD-19 Era

Table 1 show that the economic status of the 342 senior high school students doesn't affect their perceived capability of attending the elearning sessions. This gives the impression that the capability of the students in complying with the e-learning set up of the school will not be affected by the income status of their family. Since some concern that socio economic status of the students may affect their school performance if the school shift to eLearning type of lectures. It is also known that those with a college-educated parent are twice as likely to finish their courses compared to students without college-educated parents (Hansen and Reich, 2015). Despite of having the diversity in the socio-economic status of the family of SHS students it is notable that $73 \%$ of the students perceived that they are capable of attending and comply with online classes. Part of the factors considered for online learning would be the source of internet connection where as internet accessibility and the electronic tools the students will use is the backbone of online learning (LeLoup and Ponterio,2000, Chantel, 2002) noting that this kind of teaching delivery have a significant effect towards the attitudes of students in Mathematics (Yushau, 2006).

Table 2 and 3 shows the source of the students' internet connectivity and its relation to their perception of a virtual classroom and the type of electronic gadget they have relating to their capability of attending and complying with virtual and online classes. It was found that regardless of the source of the student's internet connection, it doesn't affect their perception on the workability of a virtual classroom. And likewise, the available electronic gadgets for them to use is not affecting their perception on their ability to comply with online classes. Considering that most of the students are just relying on a prepaid mobile data to be in the internet, $63 \%$ of the students and with the mean of 2.6 still are convinced that the online classes will be as good as classroom set up. There are $73 \%$ of the students and mean approval of 2.7 showing that they can attend their online class considering that $48 \%$ are only relying on mobile phones alone. As well as the quality of internet connection of the students in which $49 \%$ of the students only have fair connection, is one of the considerations. $43 \%$ of the students said that their main motivation in doing elearning activities is their internet connection.

Table 4 showed that the quality of internet connection of the students has nothing to do with their perception of an online or virtual class. As dictated by the sample, we can look separately on how the students see online classes and how it would work for them and the way they will be able to connect to it. STI Global City students, upon admission, are already given account for eLMS and will be used as for submission of school requirements and for different learning materials for them to download. With the exposure on eLMS, Table 5 shows their view on how helpful the eLMS in studying mathematics cross tabulated with the number of hours they spend using the internet in a day. It showed that the number of hours they use in browsing the internet affects their view on how helpful the eLMS in studying Math. Considering that the implementation of web-based learning activities is still new, students who lack knowledge of the internet and were not previously exposed to online learning would definitely display some form of apprehension towards it (Zarlina Mohd Zamari et al., 2012 ). The data gathered shows that $86 \%$ of the students spends at least 3 hours a day in using the internet and with the rating 7.2 out of 10 for the usefulness of eLMS in studying mathematics. It also shows that their approval on the effectiveness of eLMS depends on how much time they spend in the internet.

Online classes include providing the students with the leaning materials they needed which includes video tutorials, PowerPoint presentations, handouts etc. Educators need to educate themselves to be a good designer, content expert and competent to use technologies in terms of hardware and software to produce effective e-learning materials (Hasmawati Hassan et al., 2012 ). As the Table 6 showed, the respondents agreed, on average, that they are capable of studying mathematics at home with the use electronic materials considering that $90 \%$ of them are still in need of the teacher's validation of the lesson. In Tables 8 and 9 , the perceived mathematical ability of the students was sorted per strand. It showed through analysis of variance that the students in different strands vary significantly in their perception of their mathematical ability with the mean of 6.22 out of 10 and standard deviation of 1.53 .

\section{CONCLUSION}

In this pandemic crisis the Philippines and the whole world is going through right now, there is no doubt that e-learning and blended learning will be the new normal in the Philippine educational system. It is now just a matter of planning on how it will be implemented depending in the need of the students. Real time and self-paced online classes which are also called synchronous and asynchronous respectively are to be considered right now which was supported by the current theories seeing two basic types of teaching which can be combined in blended learning - a synchronous and asynchronous teaching (Hubackova, S., 2015). With the analysis of the data gathered from the 342 students Senior High School students of STI College Global City, the following conclusion where found:

- The quality of internet connection, types of gadget owned by the students, socio economic status and the means of connecting in the internet doesn't affect their perception of the effectiveness of BDEVlearning. This is considering the significant difference in their perceived Mathematical ability. Most of the students perceived that they are capable to attend online or distance learning and see that it is the same with actual classroom setting despite having differences in mathematical ability and regardless of their owned electronic gadgets, quality of internet connection and mean to connect in the internet.

- $76 \%$ of the students said that they learn more when watching video tutorials but it is noticeable that $90 \%$ of the students still need validation from their math teachers when studying mathematics. In average, the students "agreed" that they learn more in video tutorials and they still need validation from their teacher. This shows that despite of agreeing and having most of approval that video tutorials could truly helped the students in studying mathematics, validation from the teachers still is a vital tool for the students to gain confidence from what they acquired from a video tutorial. 
- The perception of the students in their capability of attending online lectures, watch video lectures and comply with requirements online is not affected by their socio economic status. With the diversity of the social-economic status of the students, it shows that $73 \%$ of the students said that they have the ability to comply with distance learning which can be the new normal of the Philippine education this year due to the existing threat of CoViD-19. Whatever status they have in life, it doesn't affect their view and perception of their capability of doing distance learning.

- In the view of the current prevailing type of students we have, the sample dictates that $86 \%$ of the students are spending at least 3 hours in browsing the internet. In the modern era where almost everything can be done online, this follows that the type of students schools are catering right now can be tech savvy and technologically literate. This is with the fact that the young generation, including young adults, do have increasing access and activity on the internet and the social media (Villanti, et.al.2017). It showed that this affects their approval of the Learning management System they are currently using. The data showed that their view of the effectiveness of the eLMS depends on how many hours they spend browsing the internet. 92\% of the respondents rated the effectiveness of eLMS when studying Mathematics at least 6 out of 10. After the quarantine period, the Philippine educational system will make a big change in addressing the delivery of learning of the Filipino students. STI College Global City senior High School students, as dictated by the sample, are showing a good sign of readiness in the shift of learning delivery. As shown by the result of the survey, most of the students agreed that they are capable of learning math lessons using elearning materials. It is supported by their good assessment of the usage and effectiveness of eLMS considering that most of them are always browsing the internet. This matter helped set their mind in the possibility of having online activities through the existing blended learning style of the school. Economic and technological readiness should also be considered given that $62 \%$ of the students' family are earning 30,000 pesos at most and $49 \%$ said that the quality of their internet connectivity is just "fair". Not to mention that $48 \%$ of the respondents are only relying on their mobile phones alone to connect in the internet and $27 \%$ are just using mobile data. Without stable and efficient internet connection, students will only face a lot of frustrations instead of developing and enhancing literacy based on the new technology (LeLoup and Ponterio,2000, Chantel,2002) which is also shown by the survey that $43 \%$ of the respondents uses their internet connection as their top motivator in doing BDEV-learning activities.

- The researcher has been looking forward on what would be the new set up for the delivery of lectures for the students after the Enhance Community Quarantine due to CoViD-19 pandemic. With the exposure of the respondents to a Learning Management System, their perceived capability of attending the online classes shows their willingness to embrace the BDEV-learning style of teaching. Despite having low quality of internet connectivity, types of gadgets owned and means of connecting to the internet, most of the students still find
BDEV-learning possible and doable. The fact that most of the students right now are more exposed to social media and surfing and that $86 \%$ of them spends at least 3 hours in the internet affects their approval on the effectively of Learning Management System. Since these students are already aware on how an LMS works, it is understandable that these students would embrace a school system where it is the prevailing style of teaching. It has shown that having exposed in a Learning management System gave a positive impact on their perception of a $\mathrm{BDEV}$ - learning.

\section{REFERENCES}

Chantel, R. G. (2002). New technology, new literacy: Creating a bridge for English language learners. New England Reading Association Journal, 38(3), 45.

Garcia, M. (2017). E-Learning Technology Adoption in the Philippines: An Investigation of Factors Affecting Filipino College Students' Acceptance of Learning Management Systems. The International Journal of E-Learning and Educational Technologies in the Digital Media (IJEETDM), 3(3), 118-130. https://doi.org/10.17781/P002374

Hansen, J. D., \& Reich, J. (2015). Democratizing education? Examining access and usage patterns in massive open online courses. Science, 350(6265), 1245-1248. https://doi.org/10.1126/science.aab3782

Harris, S. (2017). 5 Things To Consider When Shifting From Classroom Training To eLearning. eLearning Industry. Retrieved from https://elearningindustry.com/classroom-training-to-elearning5-things-consider-shifting

Hassan, H., Hassan, F., Zakaria, Z., \& Nor, W. A. W. M. (2012) Evaluating Mathematics e-Learning Materials: Do evaluators agree with distance learners? Procedia - Social and Behavioral Sciences, 67, 189-195. https://doi.org/10.1016/j.sbspro.2012.11.320

Hubackova, S. (2015). E-learning in English and German language teaching. Procedia - Social and Behavioral Sciences, 199(2015), 525-529. https://doi.org/10.1016/j.sbspro.2015.07.542

LeLoup, J. W., \& Ponterio, R. (2000). On the Net: Foreign Language Teacher Resources. Language Learning and Technology, 6-9.

Trung, N. T., Thu, T. T. L., \& Tan, L. M. (2012). Replacing Face-ToFace Classes by Synchronous Online Technologies: The HOU Experience. Procedia - Social and Behavioral Sciences, 67, 386-392. https://doi.org/10.1016/j.sbspro.2012.11.342

Villanti, A. C., Johnson, A. L., Ilakkuvan, V., Jacobs, M. A., Graham, A. L., \& Rath, J. M. (2017). Social Media Use and Access to Digital Technology in US Young Adults in 2016. Journal of Medical Internet Research, 19(6), e196. https://doi.org/10.2196/jmir.7303

Zamari, Z. M., Adnan, A. H. M., Idris, S. L., \& Yusof, J. (2012). Students' Perception of Using Online Language Learning Materials. Procedia - Social and Behavioral Sciences, 611-620. https://doi.org/10.1016/j.sbspro.2012.11.367 